\title{
Phase Diagram of Dilute Micelle Solutions of Polyoxyethylene Alkyl Ethers
}

\author{
Yoshiyuki EINAGA $^{\dagger}$ \\ Department of Chemistry, Nara Women's University, Kitauoyanishi-machi, Nara 630-8506, Japan
}

(Received June 21, 2007; Accepted July 20, 2007; Published September 4, 2007)

\begin{abstract}
KEY WORDS Polyoxyethylene Alkyl Ether / Wormlike Micelle / Phase Diagram / Cloud Point Curve / Critical Point / [doi:10.1295/polymj.PJ2007085]
\end{abstract}

Nonionic surfactants polyoxyethylene alkyl ethers $\mathrm{H}\left(\mathrm{CH}_{2}\right)_{i}\left(\mathrm{OCH}_{2} \mathrm{CH}_{2}\right)_{j} \mathrm{OH}$ (abbreviated $\left.\mathrm{C}_{i} \mathrm{E}_{j}\right)$ form polymer-like or wormlike micelles in dilute aqueous solutions in the $\mathrm{L}_{1}$ phase below the phase boundary, above which the micelle solutions are separated into two phases. The phase behavior is significantly varied depending upon hydrophobic chain length $i$ and hydrophilic chain length $j$. In this note are presented the results on the phase diagram (cloud point curves and critical points) culled from the literature of our own $^{1-7}$ and others, ${ }^{8,9}$ for they may be useful in understanding variation of the region of surfactant concentration and temperature, in which the micelles are formed with thermodynamical stability, with surfactant species $\mathrm{C}_{i} \mathrm{E}_{j}$.

\section{RESULTS AND DISCUSSION}

\section{Cloud point curves}

From the cloud point curves (temperature $T v s$ weight fraction $w$ curve) depicted in Figure 1, we find that the phase separation boundary shifts to the lower temperature for the micelle solutions formed with the surfactant of longer hydrophobic or polyethylene chain length $i$ and/or of shorter hydrophilic or polyoxyethylene chain length $j$. Accompanying this shift, the cloud point curve is more significantly skewed and the minimum point of the curve (critical point) shift to lower concentrations for larger $i$ at fixed $j$ or for smaller $j$ at fixed $i$. These results may be attributed to the fact that wormlike micelles of longer length are formed with $\mathrm{C}_{i} \mathrm{E}_{j}$ molecules of larger $i$ at fixed $j$ or smaller $j$ at fixed $i$ as reported in our previous papers. ${ }^{1-7}$ The phase behavior of the $\mathrm{C}_{i} \mathrm{E}_{j}$ micelle solutions highly resembles that of real polymer solutions in which cloud point curve shifts to lower temperatures and the critical point shift to lower concentrations with increasing molecular weight of the solute

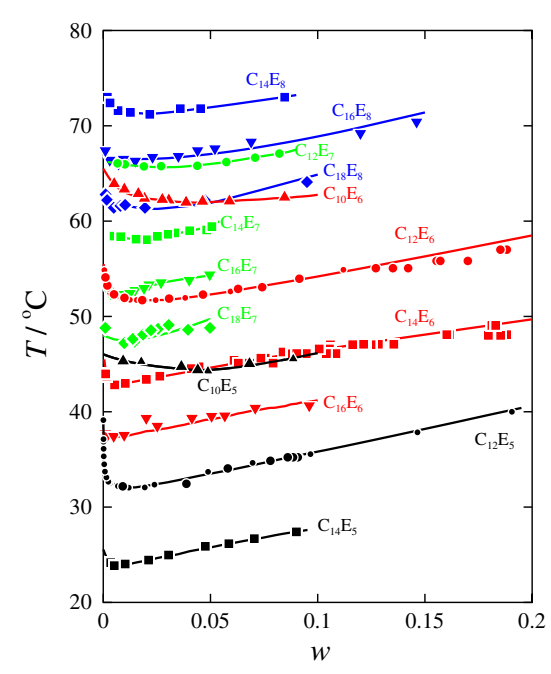

Figure 1. Cloud point curves (temperature $T v s$ weight fraction $w$ ) for the micelle solutions of various polyoxyethylene alkyl ethers $\mathrm{C}_{i} \mathrm{E}_{j}$ indicated.

polymer when phase separation of the LCST (lower critical solution temperature) type is observed. The situations behind the phase diagram of the micellar solutions are, however, more complicated than those for the real polymer solutions, since the length or molar mass of the $\mathrm{C}_{i} \mathrm{E}_{j}$ micelles increases with increasing concentration or with raising temperature.

\section{Critical Points}

Figure 2 illustrates the critical points along with the cloud point curves, where unfilled symbols represent the literature data, ${ }^{8,9}$ which were rigorously determined by sophisticated methods such as densiometry, viscometry, and so forth. It is seen that the critical points for the $\mathrm{C}_{12} \mathrm{E}_{6}$ and $\mathrm{C}_{12} \mathrm{E}_{5}$ micelle solutions are located close to the minimum points of the cloud point curves corresponding to the respective micelle solutions, suggesting that the minimum points for the

${ }^{\dagger}$ To whom correspondence should be addressed (E-mail: einaga@cc.nara-wu.ac.jp). 


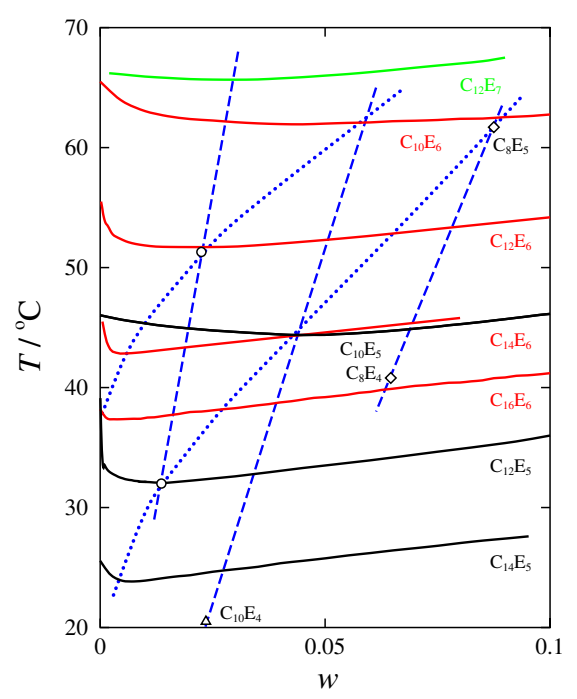

Figure 2. Critical points (unfilled symbols; dashed and dotted curves) and cloud point curves (temperature $T v s$ weight fraction $w$ ) for the micelle solutions of various polyoxyethylene alkyl ethers $\mathrm{C}_{i} \mathrm{E}_{j}$ indicated.

other cloud point curves may be regarded as critical points. The dashed straight lines represent the relationship between critical temperature $T_{c}$ and critical concentration $w_{c}$ for $\mathrm{C}_{12} \mathrm{E}_{j}\left(j=5,6\right.$, and 7), $\mathrm{C}_{10} \mathrm{E}_{j}$ $(j=4,5$, and 6$)$, and $\mathrm{C}_{8} \mathrm{E}_{j}(j=4$ and 5), while the dotted curves represent the relations between $T_{c}$ and $w_{c}$ for $\mathrm{C}_{i} \mathrm{E}_{6}(i=16,14,12$, and 10$)$ and $\mathrm{C}_{i} \mathrm{E}_{5}(i=$ $14,12,10$, and 8). It should be underscored that the shift of the critical point with the $j$ value at fixed $i$ and with the $i$ value at fixed $j$ is highly systematic. The finding may be interpreted by the fact that the longer wormlike micelles are formed with the surfactant $\mathrm{C}_{i} \mathrm{E}_{j}$ with larger $i$ at fixed $j$ of with smaller $j$ at fixed $i$. Theoretical exploration to this results is not, however, attempted in the present note, which includes only experimental findings.

\section{REFERENCES}

1. S. Yoshimura, S. Shirai, and Y. Einaga, J. Phys. Chem. B., 108, 15477 (2004).

2. N. Hamada and Y. Einaga, J. Phys. Chem. B., 109, 6990 (2005).

3. K. Imanishi and Y. Einaga, J. Phys. Chem. B., 109, 7574 (2005).

4. Y. Einaga, A. Kusumoto, and A. Noda, Polym. J., 37, 368 (2005).

5. S. Shirai and Y. Einaga, Polym. J., 37, 913 (2005).

6. Y. Einaga, Y. Inaba, and M. Syakado, Polym. J., 38, 64 (2006).

7. K. Imanishi and Y. Einaga, J. Phys. Chem. B., 111, 62 (2007).

8. K.-V. Schubert, R. Strey, and M. Kahlweit, J. Colloid Interface Sci., 141, 21 (1991).

9. G. Fritz, G. Scherf, and O. Glatter, J. Phys. Chem. B., 104, 3463 (2000). 